OPEN ACCESS

Edited by:

Albie Miles,

University of Hawaii-West Oahu,

United States

Reviewed by:

Rob Bennaton,

University of California Agriculture and Natural Resources, United States

Stacy Michelle Philpott,

University of California, Santa Cruz,

United States

*Correspondence:

Rachael Budowle

rbudowle@uwyo.edu

Specialty section:

This article was submitted to

Social Movements, Institutions and

Governance,

a section of the journal

Frontiers in Sustainable Food Systems

Received: 25 March 2021 Accepted: 20 December 2021

Published: 21 January 2022

Citation:

Budowle R and Porter CM (2022) Cultivating Community Resilience With

Agency and Sociality in Gardens for Health and Healing.

Front. Sustain. Food Syst. 5:685384.

doi: 10.3389/fsufs. 2021.685384

\section{Cultivating Community Resilience With Agency and Sociality in Gardens for Health and Healing}

\author{
Rachael Budowle ${ }^{1 *}$ and Christine M. Porter ${ }^{2}$ \\ ${ }^{1}$ Haub School of Environment and Natural Resources, University of Wyoming, Laramie, WY, United States, ${ }^{2}$ Division of \\ Kinesiology and Health, University of Wyoming, Laramie, WY, United States
}

Communities must develop ever greater resilience as they face the climate emergency and concomitant health and food system challenges. Sustainable food systems research tends to adopt broad and often theoretical social-ecological systems perspectives on resilience. Models theorize that community self-organization for mobilizing change and agency in taking planned action are key processes for community resilience. Empirically, however, how individuals come together to engage in collective action for community resilience remains little explored. In this research, we examine strategies for resilience employed by 19 participants with multiple chronic health conditions in Gardens for Health and Healing, a community-based participatory research project conducted in southeast Wyoming. Through random assignment, participants either received a home garden or designed their own 16-week wellbeing program from a menu of community health and food systems services (e.g., cooking classes, farmers' market gift certificates, home garden). Using a pre-post wellbeing survey, interviews, and 14 months of ethnographic research, we explored the role of choice-or agency - for participants' wellbeing. Survey results suggest that receiving a garden more greatly benefitted participants' physical health while designing and implementing a wellbeing plan more greatly benefitted mental health. Qualitative results find that participants in both the garden and menu conditions identified their intervention as empowering them to take action to improve their own health and wellbeing. Participants attributed their wellbeing less to what condition they were in (garden or menu), and more to the relational processes they engaged in through the project. These processes included bringing the family together; associating with friends, neighbors, and colleagues; caring for garden environments; and engaging with the community-based organization that supported both the gardens and the wellbeing plans. We find that this sociality can help promote and explain a move from individual wellbeing and agency to the collective forms of agency and self-organization necessary to cultivate community resilience for sustainable food systems.

Keywords: community resilience, agency, sociality, self-organization, collective action, multiple chronic conditions, gardens, health 


\section{INTRODUCTION}

Communities around the world must become ever more adaptive in the face of the climate emergency and associated challenges to food systems and public health. Their ability to thrive in the face of such uncertainty and change is conceptualized as community resilience. More specifically defined, community resilience is the "existence, development, [and/or] engagement of community resources by community members to thrive in an environment characterized by change, uncertainty, unpredictability and surprise" (Magis, 2010, p. 401). This concept is reasonably well theorized in the literature; however, that literature also calls for greater empirical research about how communities cultivate their resilience (Berkes and Ross, 2013; Ross and Berkes, 2014; Vaneeckhaute et al., 2017).

This study responds to that call. In southeastern Wyoming, we recruited participants who each live with multiple chronic health conditions to Gardens for Health and Healing, a communitybased participatory food systems and gardening wellbeing project. We investigated whether and how expanded participant choice-here, conceptualized as agency-supported their health and wellbeing. Through ethnographic research, we explored participants' specific strategies for resilience.

\section{COMMUNITY RESILIENCE AND WELLBEING}

Research has linked alternative agriculture and food justice strategies, including gardens, to individual and social-ecological resilience (e.g., King, 2008; Okvat and Zautra, 2011). Food systems resilience draws from these social-ecological perspectives as "capacity over time of a food system and its units at multiple levels to provide sufficient, appropriate and accessible food to all, in the face of various and even unforeseen disturbances" (Tendall et al., 2015, p. 19). While presently little applied in food systems research, community resilience frameworks integrate social-ecological systems with development and psychology perspectives on a specific, place-based scale. Models suggest that strengthening people-place relationships, social networks, and other community characteristics support two key mechanisms of community resilience: agency and self-organization (Berkes and Ross, 2013).

Below, we briefly review the most relevant literature on these key mechanisms of community resilience and the anthropological concept of sociality, which helped us to further explicate participants' strategies for wellbeing and resilience. We also discuss the literature on how gardening enhances social and individual wellbeing as relevant to the broader Gardens for Health and Healing study.

\section{Agency, Self-organization, and Sociality}

In the context of community resilience, agency is defined as community members "taking planned action to effect change" (Magis, 2010, p. 404). As one resilience scholar notes, "agency encompasses both individual-level action, premised on confidence among autonomous and able members of society that change is possible, and collective agency, expressed in the cultural, infrastructural, and communicative resources that enable collective action" (Davidson, 2010, p. 1145). Models theorize that agency relates to community self-organization in response to social-environmental changes that are unpredictable and beyond their control (Berkes and Ross, 2013), such as major weather events, climate shifts, and pandemics. In the food systems resilience literature, local self-organization refers to the ability of systems to produce new structures and systems in a specific place (Worstell and Green, 2017).

Empirical community resilience studies have begun to emerge in response to calls in the literature, particularly in disaster and tourism contexts. For example, one study of two United Kingdom flood-affected coastal communities confirmed community resilience is an emergent property of key relational capacities theorized in community resilience frameworks, including community cohesion and networks (Faulkner et al., 2018). Another interviewed New Mexico organic farmers and similarly found that they created social spaces and networks with other farmers, volunteers, customers, and organizations to support community resilience (McDaniel et al., 2021). Fewer, however, have empirically investigated key community resilience mechanisms of agency and selforganization relevant to the present study. One study explored how agency operates in community resilience through Ghanian farmers' various climate adaptation strategies. Findings suggest that reflexivity-individuals reflecting on their adaptive strategies and discussing those actions with others-may facilitate a move from individual to collective agency for resilience (Otsuki et al., 2018). Similarly, White's (2018) historical analysis of black farmers' cooperatives in the U.S. indicates that shared, futureoriented political consciousness is necessary for communities to unify for collective agency and resilience. Scholars have defined community-level agency as "a process of building relationships that increase the capacity of local people to unite, act and adapt to changing conditions," highlighting the role of social interaction in this process (Matarrita-Cascante et al., 2010, p. 738; MatarritaCascante et al., 2017).

A bridge between the above literature on social networks and collective action focused on how individuals come together to relate to each other and unify for collective and community agency and self-organization for community resilience, however, lacks both empirical and theoretical support. Due to this gap in the literature and our subsequent findings, we additionally explore the concept of sociality. Anthropologists first introduced sociality to focus on dynamic social relations, rather than static concepts of "society" and "community" (Strathern et al., 1990). Some have described it as "the range of possibilities for social coordination with others" (Ochs and Solomon, 2010, p. 69). More recent work suggests that sociality provides a lens to focus on both "the relational matrix in which humans are embedded" and "the ways in which, and the extent to which, humans in any given context come to reflect upon that matrix, and might be driven to act upon it" (Long and Moore, 2012, p. 43). This relational matrix includes not only humans, but other living beings and the environment (Long and Moore, 2012; Solomon, 2012); however, resilience perspectives suggest only humans have the agency and imagination required to act upon it (Davidson, 2010). 


\section{Gardening and Wellbeing}

Research on home and community gardening suggests that gardens yield multiple positive outcomes for wellbeing. One set of outcomes includes social wellbeing, sense of community, social ties, and community networks (Yee Tse, 2010; Soga et al., 2017; Bailey and Kingsley, 2020). Home gardeners connect with others to share garden produce, labor, and even communal meals (Freeman et al., 2012; Jehlička et al., 2018; Porter, 2018). For example, one home garden study found that gardeners shared about a third of their produce with others (Conk and Porter, 2016). This body of research has found that gardens "forge and reinforce social ties, community networks, and sense of community" (Soga et al., 2017, p. 97); "cultivate specific kinds of citizen-subjects" (Pudup, 2008); and provide a "social bridge to build community cohesion" (Gonzalez et al., 2016, p. 107). Such outcomes align with the social network characteristic of community resilience demonstrated in both the theoretical and empirical literature.

Gardening also helps to bridge people across cultures and people with nature (Longhurst, 2006; Egerer et al., 2019; de Bell et al., 2020). One form of social relationship that emerges from even potentially solitary home gardening is the dynamic one between gardener and garden through which people variably aim to control and collaborate with and even care for a nonhuman living community (Power, 2005; Okvat and Zautra, 2011; Freeman et al., 2012). People connect with the "natural" environment through relationships with plants and animals in their gardens (Bailey and Kingsley, 2020). In turn, relationships between humans and their garden environments can foster other social connections and shared community identities (Pink, 2008; Freeman et al., 2012).

A large body of research also inidcates gardens contribute to improved individual physical and mental health. Benefits include increasing fruit and vegetable intake (Armstrong, 2000; Twiss et al., 2003; Alaimo et al., 2008; Meinen et al., 2012; Litt et al., 2015), fostering physical activity (Armstrong, 2000; Park et al., 2009; Draper and Freedman, 2010; de Bell et al., 2020), reducing food insecurity (Stroink and Nelson, 2009; Corrigan, 2011; Baker et al., 2013), and improving mental health (Brown and Jameton, 2000; Austin et al., 2006; Wakefield et al., 2007; van den Berg et al., 2010; de Bell et al., 2020). The field of therapeutic horticulture has linked the gardening impacts of improved overall health and wellbeing with relational benefits. For example, a randomized controlled trial of a 15week therapeutic horticulture program with elderly participants in Singapore focused on psychological wellbeing and found significant improvements, mainly in "positive relations with others" (Sia et al., 2018, p. 2).

\section{MATERIALS AND METHODS}

The Gardens for Health and Healing project was a communitybased participatory research (CBPR) pilot that began with a randomized controlled trial design. In 2016, a community-based organization in Albany County, Wyoming-Feeding Laramie Valley-partnered with the second author at the University of Wyoming to examine health impacts of home gardens with people living with multiple chronic conditions. That year, Feeding Laramie Valley supported half the participants to start a home food garden right away. The other half, serving as the control group, was to receive a garden the following year if they wished.

Although this design aligned with Feeding Laramie Valley's emphasis on gardening, it excluded their other food justice activities, such as food sharing. More importantly, asking any participant to wait for support was ethically problematic, and even more so for people suffering serious health problems and needing immediate support. In the earlier iteration of recruiting for Gardens for Health and Healing, one potential participant stated that waiting a year for a garden if assigned to the control condition was untenable, as they may be dead within the year due to their conditions. Thus, Feeding Laramie Valley and the co-authors redesigned the study for the 2017 growing season. In addition to being a part of the academic research team, the first author joined Feeding Laramie Valley as a graduate student intern and co-coordinated Gardens for Health and Healing with the organization's Community Engagement Director. The second author continued as principal investigator. We received approval for this research from our university's Institutional Review Board \#20140307CP00334.

We randomized participants to one of two conditions. In the pseudo-control condition, participants received a home garden with installation and maintenance support as a basic standardof-care. In the intervention condition, participants designed their own health and wellbeing plan from a menu of activities within (though not necessarily limited to) Feeding Laramie Valley's programmatic network. ${ }^{1}$ In reality, both conditions presented the potential to intervene upon participants' health and wellbeing, and the garden condition did not provide a true control. However, the shift in design addressed the aforementioned ethical issues in the earlier version of the study. Accordingly, the pilot shifted from assessing impacts of gardening on health to investigating the effect of choice on health, through the planning and design process in the menu condition.

As in the first year of the study, Gardens for Health and Healing participants were adults living in Albany County, Wyoming experiencing two or more of any self-identified chronic health conditions. Additionally, participants must not have kept a food garden of eight square feet or larger in the last year. Finally, consenting participants agreed to random assignment to either the menu or the garden condition. The four participants assigned to the control condition from the previous year of the pilot were each invited to enroll in the current iteration of the study; one opted to enroll (the others were invited to receive gardens even if not enrolled in the study). In total, 19 participants qualified for and enrolled in the project, providing written informed consent for their participation.

The academic research team randomly assigned 10 participants to the garden condition and nine participants to the menu condition. After randomization, the academic ${ }^{1}$ From here on out, we refer to these study conditions as "the garden condition"
and "the menu condition," respectively. 
research team gathered pre-program quantitative health measures from each participant. These were body mass index (BMI, calculated from researcher-measured height and weight), waist circumference, hand strength, food security, self-reported pain level, and physical and mental wellness as measured by participant responses to a standardized quality-of-life and wellbeing survey, the SF-12. One textbook describes the 36question version, SF-36, as the "generic measure of choice across many diseases," with results from the 12-question version closely tracking those of the longer survey (Bowling, 2001, p. 17; Jenkinson et al., 1997).

Participants additionally completed an intake interview with the Feeding Laramie Valley co-coordinator and first author. Across both conditions, intake interview topics included their personal health and wellbeing challenges, past strategies for addressing those challenges, and what had drawn them to the project. Participants assigned to the garden condition subsequently co-designed their garden based on personal preferences and wellbeing needs identified during these interviews. Participants assigned to the menu condition subsequently engaged in a supported health and wellbeing plan mapping process during these interviews. They identified their most pertinent health challenges, how they hoped to feel at the end of the 16-week program (crafting a personalized wellbeing statement based in specific or general outcomes), assets they would bring to realizing that wellbeing statement, potential challenges to be aware of, and specific activities that would help them meet those outcomes.

Following the intake interviews, Feeding Laramie Valley staff installed four foot by eight foot raised bed or equivalent home gardens for participants in the garden condition. Participants in the menu condition began single or multiple activities selected from broad menu categories of farm-to-plate, food access, physical activity, general wellness, and gardens, which included a garden of equivalent or smaller size to those received by garden condition participants.

Menu condition participants selected a range of personalized activities using a guided and constrained choice approach facilitated by suggested activities in the menu (see Appendix A, Supplementary Materials) and program cocoordinator support. Activities and wellbeing plans were based on a detailed approximate equivalency of cost and physical, mental, and social wellbeing intensity, which the academic research team designed into the menu to support comparability of intervention and quantitative health outcomes. All but one participant chose some form of garden as part of their health and wellbeing plan, and two opted for only a large garden on par with what participants in the garden condition received.

The garden and menu programs ran for 16-weeks from mid-June 2017 to mid-September 2017 to align with a full southeastern Wyoming gardening season. Throughout the program, the first author supported participants with weekly check-ins across both conditions, including any necessary activity adjustments for menu condition participants. Feeding Laramie Valley staff provided garden maintenance and support through the program, as needed. We considered this regular interaction between participants and the community-based organization an integral part of the program, one that was common to both conditions.

Upon program completion, the academic research team gathered the same quantitative health measures to facilitate pre- and post-program participant health outcome comparison. Participants then engaged in an exit interview with first author and Feeding Laramie Valley co-coordinator, which focused on their experiences gardening or with their various health and wellbeing activities. Topics included how their experiences aligned with their initial expectations for participation in the project, impacts (if any) that the project had on their health and wellbeing, and their experience of assignment to either the garden or menu conditions.

The main focus of the present study is analysis of qualitative data emerging from extensive ethnographic fieldwork that explored whether and how agency impacted menu condition participants' experiences of their wellbeing, including in comparison with those assigned to the garden condition. These ethnographic methods include the person-centered intake and exit interviews described above, which focused on individual participants' experiences in relation to the broader project context (Levy and Hollan, 2015).

Additionally, methods include 14 months of participant observation (DeWalt and DeWalt, 2011) conducted by the first author from August 2016 to October 2017. As a graduate intern and program co-coordinator with Feeding Laramie Valley, she was involved almost daily in supporting and delivering gardens and other food system and community-based wellbeing activities with participants. Her field notes (Sanjek, 1990) included interactions with academic public health researchers from the University of Wyoming and the Feeding Laramie Valley team. Mainly, her field notes focused on interactions with participants. These recorded and reflected upon her engagement with participants including helping to prepare and plant their gardens; checking in at least weekly with each participant via email, text message, or in-person; and both participating in and designing and delivering activities, including cooking classes, farmers' market trips, food shopping and budgeting workshops, and a public presentation through which some participants shared their program experiences.

We audio-recorded all interviews ( $n=38$, including a pre- and post-program interview for all 19 participants) and then created and corrected verbatim transcripts. The first author deductively analyzed interviews (Bernard, 2006) around the central research focus on the role of choice or agency in participants' wellbeing. Analysis compared participants' experiences in each condition generally and with agency, action, and choice within their respective conditions, specifically. This analysis also included participants' related initial reasons for enrollment in Gardens for Health and Healing from preprogram interviews. We also drew on a comparison of pre- and post-program quantitative health outcome measures to further illuminate qualitative analysis of deductive research questions about the role of choice in participants' wellbeing. While this deductive approach shaped initial analysis, inductive analysis based in grounded theory allowed additional themes beyond agency to emerge (Glaser and Strauss, 1967; Strauss and Corbin, 
1990; Miles and Huberman, 1994). Relational processes emerged as the most salient element of wellbeing alongside agency for participants in both conditions. We organized these processes into four major thematic and analytical categories as outlined below. In addition to summarized interview data supported with exemplative participant quotes, field notes from the first author's participant observation augment interview data for a synthesized, ethnographic analysis.

\section{RESULTS}

Participants' ages ranged from 21 to 65 years old and included 17 people who identified as women and two who identified as men. All were managing at least two chronic health conditions, including fatigue, chronic pain, depression, anxiety, and obesity. We had $100 \%$ participant retention.

\section{Participants' Health Perspectives at Enrollment}

Upon initial intake to the project, participants across both conditions described feeling as though they lacked control over their health and wellbeing. One participant described how their health and weight had "snowballed" over time. Another participant very directly stated "my diabetes is not under control." One said that previous approaches to addressing her wellbeing were ineffective, and she had all but "stopped trying things about a year ago, because they're not working." Another shared, "my mental, emotional challenges keep me feeling stuck and unhealthy" and shared concerns that those challenges would soon "spiral out of control." Nearly every participant shared their experiences of how physical conditions, along with depression and anxiety, impacted both their personal health and their social relationships.

However, participants shared that simply enrolling in the project provided them with a sense of control and motivation to address their own challenges. Several explained that they hoped the project would help them "get off the meds." Others spoke about wanting support to learn how to garden, for example, to "feel like I have that confidence, like I can actually do something good." One summed up her reasoning for enrolling in Gardens for Health and Healing as wanting to "feel better, so I can actually do something with my life." Another framed his reason for participating as "this summer I want to heal as much as I can. Even if the pain doesn't go away, the mental part, that I can control that. I can do something about that."

\section{Agency and Wellbeing in Menu and Garden Conditions}

In exit interviews, participants reflected on their experiences of choosing their own health and wellbeing activities to meet their self-defined health goals in the menu condition or receiving a garden.

Participants in the menu condition $(n=9)$ appreciated the ability to identify their own desired outcomes and then design their health and wellbeing plan to achieve them. As one participant said, "Everybody's different, so you have to adapt to that. You know yourself better than other people do. You know what you need." Another explained that the menu approach worked well for her with "being able to know what I want in the future and then set the goals that lead me to that. I feel I'm kind of a certain person that [if] it's my idea, I can do it, but if it's your idea, ehh..." Several mentioned that setting outcomes and the plan for getting there helped them with "sticking with" the programs they had designed, not only for the 16 weeks but also possibly beyond. For example, one participant encapsulated this by saying she designed her wellbeing plan to intentionally develop new skills for long-term maintenance of her wellbeing:

When I was choosing the different things like the shopping, the budgeting, and the cooking classes, I thought it was a good mix of how to help me to probably reduce my stress... To learn how to acquire or sharpen those skills-I knew I needed that.

Another person shared feelings of shame about her health, which she developed over years of being told what she "needs" to do for exercise and diet. She noted that identifying her own outcomes and developing a plan offered a less shaming and even fun approach to nurturing her own wellbeing.

One appreciated the flexibility of being able to adjust her activities as she moved through the project. Although in practice she largely maintained the same activities, she appreciated knowing she had the option for flexibility, which assignment to the garden condition would not have afforded. Another shared, "I enjoyed the experience of choosing. It was hard to choose, because I would love to do all of those things if I had the time and the ability."

Participants in the garden condition $(n=10)$ did not design their own wellbeing intervention, but the exit interviews suggest they valued their assigned condition nonetheless. Some said that the garden condition was "the one I wanted" or otherwise felt "special" for receiving one. As in the menu condition, participants identified a garden assignment as something that "worked" for them and would benefit them over the long-term. For example, one noted:

I'm so happy to have had [the garden] and happy that I can continue doing it. It's not like it was a one-time thing, and now I have to figure out what to do to garden. I already know what to do.

Some appreciated that gardening was a wellbeing activity they could do on their own time. The responsibility of caring for the plants also motivated them. One said she received "the garden of my dreams," and explained how the garden made her want "to get up and do things, where maybe I didn't want to before.” Two other participants shared similar sentiments:

\footnotetext{
The other group would have been okay, but I'm really good at saying "oh you know what? I've been out all week and when I get home from work, I don't want to go back out." It would be really easy for me to say "nah" and skip it. I have a garden; it's facing me every day when I go in and out of my door. You can see the growth and see where it's going to help, and it's just there.
} 
TABLE 1 | Average change in participant wellness in each condition, on the 0-100 point scale of the SF12v2 quality of life/wellbeing survey. For an individual, a change of 5 points or more is generally considered clinically meaningful.

\begin{tabular}{lcc}
\hline & $\begin{array}{c}\text { Garden participants } \\
(\boldsymbol{n}=\mathbf{1 0})\end{array}$ & $\begin{array}{c}\text { Menu participants } \\
(\boldsymbol{n}=9)\end{array}$ \\
\hline Change in physical wellness & +5.02 & +2.38 \\
Change in mental wellness & +1.35 & +4.75 \\
\hline
\end{tabular}

I think that having time to take some of those other classes, that's why I struggled [in the past], why I don't do it. I think it would have been harder to make sure that I followed my own wellness plan, so having the garden was a good responsibility to have, but it wasn't overwhelming either.

Another gardener mentioned how gardening motivated her, and she also valued the food choices that gardening provided:

[It's] something to do every day. I knew I had a goal every day, that I needed to do it, or I wouldn't have a garden, so I liked that experience and the challenge of it... It really helped me know what I wanted to eat and choose some healthy things, as well.

Even participants who had initially hoped to receive assignment to the menu condition ultimately reasoned that they were glad to be in the garden condition. One wondered how things might have been different in the menu condition and if she would have realized greater health improvements more quickly. However, echoing sentiments of gardeners quoted above, she was ultimately "glad that I was in the garden group, because that's something I definitely feel like I could sustain.” Another participant reasoned that the garden condition turned out better for her than the menu condition due to the opportunity for long-term benefits:

I think I could have definitely benefitted from the guidance on the other end of things too, but I was really excited to have the garden, because I think it'll be something long-term moving forward that we can continue to do, whereas in the other group, I probably wouldn't continue.

Quantitative analyses of self-reported physical and mental wellness on the SF-12 survey also reflect that participants experienced wellbeing benefits in both conditions. Gardening participants may have realized greater improvements in their physical health while menu participants may have had greater improvements in mental wellness (see Table 1). Though the small sample size within this pilot study did not provide sufficient power to test for statistical significance, these quantitative trends align with the qualitative results. Also, the mean mental wellness improvement for menu participants and physical improvement for garden participants are generally considered clinically significant and within clinical significance ranges identified in previous studies of specific health outcomes (Busija et al., 2011; Parker et al., 2013; Díaz-Arribas et al., 2017).

None of the other quantitative measures-BMI, food security, hand strength and waist circumference - indicated clinically or statistically meaningful changes with or between groups. Participants in both conditions rated their overall pain slightly lower, on average, after the intervention. On a 10-point selfassessment scale, the gardening group's pain rating decreased by 0.9 points and the menu group by 1 point.

\section{Sociality and Wellbeing Across Conditions}

Further analysis of exit interviews showed that relational processes and social connection overwhelmingly emerged as the most salient shared aspect of wellbeing for participants, regardless of the condition to which they were assigned. As outlined below, four themes of relational processes and social connected emerged for participants in Gardens for Health and Healing: bringing the family together; associating with neighbors, friends, and co-workers; caring for and relating to garden environments; and engaging with a communitybased organization.

\section{Bringing the Family Together}

While Gardens for Health and Healing was an individualized health and wellbeing intervention, many participants reported enhanced relationships with their families. They engaged family members directly and indirectly in gardening or their other wellbeing activities. For example, several participants mentioned calling their mothers for gardening advice, which one described as an opportunity for "bonding."

Other participants experienced direct involvement from family members that they had not initially expected. Penny's ${ }^{2}$ boyfriend, for example, had initially been resistant to the project and the garden, telling her, "do your thing." As the gardening season progressed, he increasingly became involved, from giving input, to weeding, to eventually helping her build a greenhouse for the following season. "It's very family inclusive," she said about the garden. Pete, who participated in cooking and ballet classes, frequently described how the experience brought him closer to both of his sisters-one who likes to test new recipes and one who was studying dance. Frisco explained that her oldest son, a junior in college who lived on his own, would call to ask if she had extra vegetables or if he could come over for dinner to eat from the garden. She cited "bringing the family together" as the single greatest outcome from gardening, elaborating:

Everybody in the family got involved in working in the garden, watering the garden, pulling weeds, planting, etc., so that was nice. And then, just reaping the harvest of it... I think the huge one for $m e$ is the participation from my family and the closeness that I felt like it brought us.

Sadiejo's experience in the project centered around strengthening family relationships through gardening. Nearly each time the first author visited to help in her garden, one of her two adult daughters would join to garden or take pictures. She particularly enjoyed involving her 5-year-old grandson and explained how excited he was to pick tomatoes and carrots, plant his own pot of beans, and share pictures with Feeding Laramie Valley staff. Now that her health was improving-she no longer needed a

\footnotetext{
${ }^{2}$ Participants selected codenames during their pre-program health data collection and intake sessions, which we use throughout the Results section to protect participant confidentiality.
} 
cane to walk, for example-she was most excited to spend more active time with her grandson in the garden and elsewhere. As she developed a new lifestyle based in growing and cooking her own vegetable-centric food, she encouraged her daughters and mother, who similarly live with multiple chronic health conditions, to do the same.

\section{Associating With Neighbors, Friends, and Co-workers} In addition to forging and enhancing familial relationships, participants strengthened or even developed new relationships as a result of their wellbeing activities, including with neighbors, friends, and co-workers. Many found that both participating in activities, like gardening, meditation, and hiking with others, and even talking about those experiences with friends and coworkers helped to reduce their anxiety and depression by pushing them to expand their circle of associations.

One participant explained that her garden gave her "avenues to talk to people I normally wouldn't." Previously, her struggles with overeating had prevented her from visiting other peoples' homes if food would be available, because she would experience panic attacks when the potential for deviating from her meal plan was too great. When she was invited to a small party to watch a football game and celebrate a fellow church member's birthday during her gardening experience, she planned together with another party guest and friend how to accommodate her food needs to help her maintain control. She was able to enjoy the event with other people, saying, "I figured out I can do these things... I was able to control that," which she explained as something she never would have been able to previously do.

Other participants engaged in networks of exchange, sharing produce from their gardens. Silver, who experienced severe depression, hosted neighborhood garden dinner parties and shared food with women from her church who she said otherwise "don't have money or the ability to have a lot of fresh vegetables." Raer also shared vegetables with neighbors living in her multifamily rental home. She was particularly delighted when a neighbor who claimed he did not like tomatoes noted how much better tasting Raer's tomatoes were than store-bought ones. She also swapped squash and cucumbers for grapes from a next-door neighbor. Beyond a simple act of exchange, Raerwho was striving to increase her interaction with other people after recently suffering a stroke-noted how sharing "opened up conversation" with her neighbors.

In addition to neighbors, participants formed or enhanced associations with co-workers and friends who gardened. Participants shared knowledge, skills, and even stories of excitement about their wellbeing experiences, including a sense of feeling special for being able to participate in Gardens for Health and Healing. Bird explained, "I never thought I'd be talking about gardening [with my boss and coworker], but it was nice, we could compare notes" and even engage in friendly competition about growing different plants.

Some participants enhanced virtual associations through the project, particularly by sharing photos and anecdotes about their garden challenges and successes via text messages and on social media. One interpreted online associations as "a fun way to connect with people who shared garden stuff, with people in the community." For Kitty, her garden and ballet class activities provided a means to connect with people outside of an online space. When asked about any connections she had made with people during the project, Kitty said:

Oh, I actually have some now. Pretty much all of them are online, so getting out into the real world and doing some actual "human-ing" is good, just getting out there and meeting people. I still have a long way to go on that, but it [the project] helped.

Participants developed entirely new and, for some, unexpected associations through gardening and project participation. After gaining experience and confidence with her own garden, Frisco volunteered to manage the school garden and advise the garden club at the elementary school where she teaches. She described making connections with both students and people otherwise unconnected with the school:

We've had people in the community stop by and comment on our garden and how beautiful it is. I currently have 56 children involved in garden club, when I expected maybe six. I have 56 little munchkins around me every other week to learn about gardening. We're kind of learning together.

While the first author was working with Sadiejo in her garden at her apartment complex one morning, Sadiejo's upstairs neighbor approached her and asked, "How's your day?" After Sadiejo said hello to him in return and he left, she explained that he had autism and had never previously talked with her and rarely spoke to anyone in the complex or anyone he doesn't know. She excitedly further explained her understanding of his newfound engagement with her saying, "It's because of the garden."

\section{Caring for and Relating to Garden Environments}

Beyond human social relationships, participants in both conditions who gardened developed relationships with their gardens and the non-human worlds surrounding those gardens. Most frequently, garden relationships manifested in an ethos of care for the garden as a living thing. Despite harsher weather conditions at her home on the prairie on the outskirts of town, including an early season hailstorm that required replanting, HapDay stressed the importance of doing everything possible to support her medium-sized garden, saying, "It was kind of like a baby; you have to keep it alive."

A similar sense of care interwoven with responsibility emerged for several other participants, including an expression of sadness when plants died in the challenging Laramie climate. Bird, for example, explained a sense of loss over watching a zucchini plant die and how she wished her garden was more successful. She stated, "I wanted to make sure that I took care of this garden, because it's another living thing." The responsibility of caring for the garden, much like caring for her dog, additionally helped her to think outside of herself to manage the depression that was further exacerbated by an unexpected surgery that nearly 
immobilized her during most of the Gardens for Health and Healing program. Similarly, Purple equated her relationship of care with the garden to caring for her cat. Providing food and water for both living entities at the same time everyday created a consistent daily activity of responsibility and care. She said, "I exceeded my own expectations, because I was able to make sure that was my top priority."

Raer focused on the animal world developing through her garden and shared stories of specific animals who returned throughout the gardening season during her weekly project check-ins. Crows ate her beans and, "Itty Bitty," the wild rabbit she named and watched grow during the season, ate the few peas that actually grew. Raer saw these animals not as pests, but as visitors who "felt safe" because she shared food with them. Similarly, Glorious described an entire social world or living community with which she related in the garden, including "all the sunflowers, and it attracted a lot of pollinators, especially during the butterfly migration last week, lots of visitors, squirrels, birds."

Glorious also equated gardening to being in a relationship. She consistently talked about how, as a middle-aged woman, the loss of her spousal relationship in a recent divorce informed her decision to participate in the project. She recalled times of happiness when she kept a garden in her former shared home with her now ex-husband, and she chose a garden as the sole activity for her wellbeing plan to independently reclaim some of that happiness and heal from the divorce. At the end of the project, Glorious stated:

I loved the relationship I had with the food... I think that relationship-and this may sound weird, because I'm singlebut it was almost like being in a relationship. It gave me that same kind of emotional connection with my garden...It was right in front of me every day, and actually, it helped me, because I had to interact with it every day. It needed me, and I needed it.

In this way, her garden provided more than a metaphorical relationship but an actual reciprocal social connection.

\section{Engaging With a Community-Based Organization}

Participants in both groups explained during their intake interviews how their chronic conditions affected their relationships and contributed to feelings of isolation. Some participants noted that having a built-in opportunity for developing connections between the first author and Feeding Laramie Valley staff through garden installation and maintenance, wellbeing activities, and weekly check-ins was an unexpected benefit of their participation.

Several participants reported benefiting from their regular interactions with organization staff in their wellbeing activities, both as a motivation and confidence boost for engaging in those activities and for direct companionship. Kitty, for example, who selected a medium garden and adult ballet classes, said that these activities gave her "strength," both physically and emotionally, and "an incentive to actually get out of the house and do something." She highlighted the "friendship element" of her activities with the first author and Feeding Laramie Valley staff and wanted to "stay involved in the future, as I like you all and had some fun." Others shared that meeting new people through weekly activities helped to reduce their anxiety.

Many participants said that they valued the weekly project text messages and emails from Feeding Laramie Valley for all wellbeing and gardening activities. This supported developing a connection and providing a sense of potential availability of staff to answer questions and troubleshoot challenges together if they arose. For example, Frisco said:

The support from you all in coming out with your smiling faces each time, and being willing, even if we didn't choose to have you come out, just knowing that support was there was very nice to have and not expected at all. I just felt like that [support] was a wonderful thing to feel successful as a gardener.

Pete, a university student, chose cooking, shopping, and budgeting classes. He valued learning through weekly visits to Feeding Laramie Valley and markets across town about multiple opportunities to connect with the "community" that he had not previously known about. Penny similarly viewed Feeding Laramie Valley staff availability and engagement with her garden as a potential opportunity for other people to also connect with "the community," saying:

You guys' excitement when you'd come out and help put the garden in, it's so contagious. I just appreciate you guys' enthusiasm. And, moving forward with these things and building this and making it grow, I think it's an amazing resource that I hope Laramie as a community can tap into, because I learned a lot, and I had so much fun doing it.

Some participants identified social connections with Feeding Laramie Valley in its larger role as a community-based food justice organization, not just as the service provider in Gardens for Health and Healing. They began to look for reciprocal opportunities to engage with the organization and "give back" to other people. Pete, for example, mobilized dozens of volunteers from his church to volunteer with Feeding Laramie Valley after his summer wellbeing program ended. For another participant, this kind of "giving back" was a central focus of her wellbeing reflection:

It was wonderful to be able to come here and drop food off and have that connection... It felt good to donate food. That was also really good for my self-esteem, feeling like I was giving back... It was reciprocal... the sense of connection, service, and like I mentioned, bringing food and feeling like a part of something bigger than myself.

Another participant in the garden condition who was unaware of Feeding Laramie Valley's existing food sharing programs at the time actually recommended food sharing for the future:

I would say in the future that could be an avenue: if there's so much that we can't use it for our family, are there other families that could 
use it? Or, could it be brought down [to Feeding Laramie Valley] for the community?

Toward the end of the project, Feeding Laramie Valley hosted its annual Higher Ground Fair, which celebrates rural living in the Rocky Mountains. Staff invited three participants to publicly share their experiences with Gardens for Health and Healing in a presentation panel. One wrote and read out loud a short story about her garden and ballet classes. Another narrated a picture slideshow of her garden. The third screened a short garden video she had produced. In her exit interview, the videographer explained her eagerness to participate in the panel, to give back and help engage other people in gardening:

I feel like you guys have brought all the experience, all the supplies, all of the knowledge, all of that groundwork that I needed. For me to offer something back, I just felt like that's something I wanted to do to tell other people about it, if they didn't know about it, and hopefully they can get involved too.

Finally, one participant closed her exit interview with a challenge for Feeding Laramie Valley indicative of hopes for next steps for collective action beyond the project, saying, "Where do we go from here? You started something. Are you going to finish it?"

\section{DISCUSSION}

As our results show, participants reported that Gardens for Health and Healing was beneficial or even integral to their wellbeing, regardless of the condition to which they had been assigned. They provided similar reasoning for the project's contribution to their wellbeing across conditions, such as manageability, long-term sustainability, and providing an opportunity for acting on their multiple chronic conditions and challenges. Ethnographic analysis of these shared experiences of agency and wellbeing across conditions found that relational processes and social connection overwhelmingly emerged as the most salient shared aspects of wellbeing for participants in both the menu and garden conditions.

Participants understood their respective conditions as key to supporting their health and wellbeing. In the menu condition, participants described having an expanded choice set through which to exercise their agency as integral to their wellbeing. They identified both having a choice of activities and being able to identify their own outcomes and activities as key components of that wellbeing. Additionally, participants identified choice as contributing to their motivation to engage in activities and their ability to develop long-term wellbeing strategies. Participants in the garden condition also found assignment to that condition was just as valuable to their wellbeing. For many, receiving a garden was what they had hoped for in their participation, and they described constrained choice as beneficial to them. Several identified opportunities to act for their own wellbeing through the garden and asserted that the garden provided them a manageable task to commit to each day and a sustainable pathway for wellbeing in both the near and long-term. In both conditions, participants actualized individual agency to support their wellbeing and resilience, both within and beyond the project. The actuality of action is key to agency in community resilience (Magis, 2010).

Additionally, across both conditions, participants developed relationships that they identified as integral to their wellbeing. They engaged in four main modes of relational processes through Gardens for Health and Healing: bringing the family together; associating with neighbors, friends, and co-workers; engaging with a community-based organization; and, for those who either received a garden through their condition assignment or otherwise selected some form of garden, caring for and relating to garden environments.

Our findings indicate that community resilience frameworks can benefit from the dynamic understanding of relationships provided by the concept of sociality, moving beyond more static, theorized community characteristics of people-place relationships and social networks. The concept of sociality illuminates these processes as occurring within the dynamic sociocultural matrix that participants developed through the Gardens for Health and Healing project. Sociality is a means for otherwise loosely connected individual agents, such as Gardens for Health and Healing participants, to forge new connections or strengthen and deepen existing ones. Participants reflected on and acted within and through this communitybased participatory project as a dynamic relational matrix that undergirds sociality (Long and Moore, 2012). Within their growing sociality matrix, participants began to engage in reflexivity by performing individual actions, reflecting on them, and communicating with others about those actions. We provide an empirical basis for how reflexivity, otherwise only hypothesized in community resilience models, can support a move from individual to collective agency for community resilience (Otsuki et al., 2018).

Reflexively coordinating and communicating with others requires actively building relationships with a range of human and non-human beings (i.e., sociality). Models note the importance of self-organization in response to change and uncertainty for community resilience but do not explain how it occurs in specific contexts (e.g., Berkes and Ross, 2013; Worstell and Green, 2017). Investigating unique forms of sociality, as we have done here, can clarify the myriad ways in which self-organization for community resilience becomes possible. As with community garden spaces that cultivate "emplaced sociality" and the potential for agency (Pink, 2008), the project provided opportunities for self-organization to emerge through participants' social connections. The relationships that participants developed with Feeding Laramie Valley as a community-based organization, particularly those that prompted participants to "give back," share their experiences at a public event, and inquire about next steps upon the project's completion, are notable. They are indicative of the potential provided by the project for moving from individual wellbeing practices to collective action and self-organization for community resilience.

A "worlding" perspective on sociality, wherein participants create social worlds together through lived relationships with others that support fuller participation in those worlds (Haraway, 2008; Solomon, 2012), provides a useful lens here. Worlding 
allows that humans relate with other entities such that their "agencies are formed dialectically through co-participation in activities, performances, and discourses" (Solomon, 2012, p. 115). This shared agency-based aspect of sociality is also particularly relevant to its potential role in catalyzing a move from individual to collective agency for community resilience. Our results suggest that participants' reported benefits across both conditions emerged from taking individual action for their wellbeing. Perhaps even more importantly, however, those benefits emerged from co-produced, shared agency that they developed through their participation in Gardens for Health and Healing.

Furthermore, sociality can deepen understandings of social aspects of health in the gardening and food systems literature. Beyond developing generic social ties and networks of exchange, participants engaged in various and unique modes of sociality as relational processes with family, friends, their gardens and the living environments surrounding them, and with a communitybased organization through gardening and related food system and wellbeing activities. These modes suggest the range of possible "socialities" between humans, each other, and other life in particular configurations (Long and Moore, 2012; Solomon, 2012). As other gardening studies have shown, even potentially solitary activities like home gardening allowed participants to create new social worlds.

In addition to sociality, we suggest community resilience frameworks themselves can provide an important contribution to food systems resilience research on a place-based scale. This research tends to employ the broad social-ecological systems resilience perspectives we previously mentioned more so than those on a community scale (e.g., Tendall et al., 2015; Prosperi et al., 2016; Walsh-Dilley et al., 2016; Worstell and Green, 2017). Even studies of smaller scale regional and local food systems resilience often adopt these broader social-ecological systems perspectives as opposed to community resilience frameworks (e.g., Biehl et al., 2018; Jehlička et al., 2018; Skog et al., 2018). Those earlier gardening and food systems studies that do employ the terminology of "community resilience" predate the conceptually robust, integrated frameworks that we use and advance here (e.g., King, 2008; Okvat and Zautra, 2011). However, we posit that fostering community resilience builds necessary (though not sufficient) foundations for larger systemic resilience.

We suggest that more empirical investigations aimed at operationalizing theorized community resilience models will add practical depth to food systems resilience research. This study and our related research on intergenerational resilience for Indigenous food sovereignty (Budowle et al., 2019), provide examples of these kinds of empirical, contextualized, community-based approaches to both that scholarship and related practice. Moreover, a similar study with a larger sample size and a delayed-intervention control group may help discern if either menu or garden conditions yield any statistically significant quantitative health outcomes within or between groups. Additionally, following the participants for more than one season would help to trace long-term outcomes, whether and how participants sustain activities after interventions or programs end, and the broader role of sociality in contributing to community resilience.

Now that Gardens for Health and Healing has ended, disjuncture-an aspect of sociality in which people disengage from associations and shift or end relationships-is possible (Amit, 2015). The relational process developed by participants through the the project have likely changed or even discontinued. Though many participants talked about the sustainability of their health and wellbeing actions, we do not know whether or not participants remain engaged in individual or collective action surrounding gardens and food systems. Regardless, participants built richly textured social worlds through the project, which provided the possibility and a pathway for collective action for community resilience.

In sum, we suggest that this kind of empirical research on community resilience is helpful for understanding and developing overall food systems resilience. We found that both gardening and designing and implementing menu-based health interventions fostered agency and helped participants engage in a range of relational processes. We conclude that sociality can help promote and explain a move from individual wellbeing and agency to the collective forms of agency and self-organization necessary to cultivate community resilience for sustainable food systems.

\section{DATA AVAILABILITY STATEMENT}

The datasets presented in this article are not readily available, because interview and ethnographic data are highly personal and difficult to fully de-identify. However, SF-12v2 data are available upon request to the corresponding author.

\section{ETHICS STATEMENT}

The studies involving human participants were reviewed and approved by The University of Wyoming Institutional Review Board reviewed and approved this study involving human participants. The participants provided their written informed consent to participate in this study. Written informed consent was obtained from the individual(s) for the publication of any potentially identifiable images or data included in this article.

\section{AUTHOR CONTRIBUTIONS}

$\mathrm{RB}$ conducted the interviews and ethnographic research, analyzed qualitative data, and wrote the first version of this manuscript as part of her dissertation research. CP was the principal investigator of the overall Gardens for Health and Health study, mentored the first author's work, and co-wrote this version of the manuscript. All authors co-designed the study reported here, including the menu of suggested options for participants in the menu condition, with support, review, and approval by Feeding Laramie Valley. 


\section{FUNDING}

Gardens for Health and Healing was supported with Wyoming INBRE funding, with grants from the National Center for Research Resources (5P20RR016474-12) and the National Institute of General Medical Sciences (8 P20 GM103432-12) from the National Institutes of Health.

\section{ACKNOWLEDGMENTS}

Feeding Laramie Valley staff and leadership were integral to this research, particularly Lina Dunning and Gayle Woodsum who led project implementation and partnered with us on study conceptualization. Additionally, we greatly appreciate

\section{REFERENCES}

Alaimo, K., Packnett, E., Miles, R. A., and Kruger, D. J. (2008). Fruit and vegetable intake among urban community gardeners. J. Nutr. Educ. Behav. 40, 94-101. doi: 10.1016/j.jneb.2006.12.003

Amit, V. (2015). Disjuncture: The creativity of, and breaks in, everday associations and routines. In V. Amit (Ed.), Thinking through sociality: An anthropological interrogation of key concepts (pp. 21-46). New York: Beghann Books.

Armstrong, D. (2000). A survey of community gardens in upstate New York: Implications for health promotion and community development. Health Place. 6, 319-327. doi: 10.1016/S1353-8292(00)00013-7

Austin, E. N., Johnston, Y. A. M., and Morgan, L. L. (2006). Community gardening in a senior center: A therapeutic intervention to improve the health of older adults. Therapeut. Recreat. J. 40, 48-57. Available online at: http://js. sagamorepub.com/trj/article/view/965 (accessed March 1, 2021).

Bailey, A., and Kingsley, J. (2020). Connections in the garden: opportunities for wellbeing. Local Environ. 25, 907-920. doi: 10.1080/13549839.2020.1845637

Baker, E. A., Motton, F., Seiler, R., Duggan, K., and Brownson, R. C. (2013). Creating community gardens to improve access among African Americans: A partnership approach. J. Hunger Environ. Nutr. 8, 516-532. doi: 10.1080/19320248.2013.816986

Berkes, F., and Ross, H. (2013). Community resilience: Toward an integrated approach. Soc. Nat. Resour. 26, 5-20. doi: 10.1080/08941920.2012.736605

Bernard, H. R. (2006). Research Methods in Anthropology: Qualitative and Quantiative Approaches (4th ed.). Lanham, Maryland: AltaMira Press.

Biehl, E., Buzogany, S., Baja, K., and Neff, R. (2018). Planning for a Resilient Urban Food System: A Case Study from Baltimore City, Maryland. J. Agric. Food Syst. Commun. Develop. 8, 39-53. doi: 10.5304/jafscd.2018.08B.008

Bowling, A. (2001). Health-related quality of life: Conceptual meaning, use, and measurement. In: Measuring disease: A review of disease-specific quality of Life measurement Scales (2 ${ }^{\text {nd }}$ ed., pp. 1-19). Buckingham: Open University Press.

Brown, K. H., and Jameton, A. L. (2000). Public health implications of urban agriculture. J. Public Health Policy. 21, 20-39. doi: 10.2307/3343472

Budowle, R., Arthur, M., and Porter, C. (2019). Growing intergenerational resilience for Indigenous food sovereignty through home gardening. Agric. Food Syst. Community Dev. 9, 145-165. doi: 10.5304/jafscd.2019.09b.018

Busija, L., Pausenberger, E., Haines, T. P., Haymes, S., Buchbinder, R., and Osborne, R. H. (2011). Adult measures of general health and health-related quality of life: medical outcomes study short form 36-item (SF-36) and short form 12item (SF-12) health surveys, nottingham health profile (NHP), sickness impact profile (SIP), medical outcomes study short form 6D (SF-6D), health utilities index mark 3 (HUI3), quality of well-being scale (QWB), and assessment of quality of life (AQoL). Arthr. Care Res. 63, S383-S412. doi: 10.1002/acr.20541

Conk, S. J., and Porter, C. M. (2016). Food gardeners' productivity in Laramie, Wyoming: More than a hobby. Am. J. Public Health. 106, 854-856. doi: 10.2105/AJPH.2016.303108

Corrigan, M. P. (2011). Growing what you eat: Developing community gardens in Baltimore, Maryland. Appl. Geograp. 31, 1232-1241. doi: 10.1016/j.apgeog.2011.01.017 the Gardens for Health and Healing Community Advisory Board and community partners who delivered programs. Alyssa Wechsler, former research scientist and Gardens for Health and Healing project manager at the University of Wyoming, provided invaluable coordination and implementation of health data collection and broader study design. Most importantly, we are grateful to the participants who shared their time and wellbeing and gardening experiences with us.

\section{SUPPLEMENTARY MATERIAL}

The Supplementary Material for this article can be found online at: https://www.frontiersin.org/articles/10.3389/fsufs. 2021.685384/full\#supplementary-material

Davidson, D. J. (2010). The applicability of the concept of resilience to social systems: Some sources of optimism and nagging doubts. Soc. Nat. Resour. 23, 1135-1149. doi: 10.1080/08941921003652940

de Bell, S., White, M., Griffiths, A., Darlow, A., Taylor, T., Wheeler, B., et al. (2020). Spending time in the garden is positively associated with health and wellbeing: Results from a national survey in England. Landscape Urban Plann. 200, 103836. doi: 10.1016/j.landurbplan.2020.103836

DeWalt, K. M., and DeWalt, B. R. D. (2011). Participant observation: A guide for fieldworkers (2nd ed). Plymouth, UK: AltaMira Press.

Díaz-Arribas, M. J., Fernández-Serrano, M., Royuela, A., Kovacs, F. M., GallegoIzquierdo, T., Ramos-Sánchez, M., et al. (2017). Minimal clinically important difference in quality of life for patients with low back pain. Spine. 42, 1908-1916. doi: 10.1097/BRS.0000000000002298

Draper, C., and Freedman, D. (2010). Review and analysis of the benefits, purposes, and motivations associated with community gardening in the United States. J. Commun. Pract., 18, 458-492. doi: 10.1080/10705422.2010.519682

Egerer, M., Ordóñez, C., Lin, B. B., and Kendal, D. (2019). Multicultural gardeners and park users benefit from and attach diverse values to urban nature spaces. Urban Forest. Urban Green. 46, 126445. doi: 10.1016/j.ufug.2019. 126445

Faulkner, L., Brown, K., and Quinn, T. (2018). Analyzing community resilience as an emergent property of dynamic social-ecological systems. Ecol. Soc. 23, 24. doi: 10.5751/ES-09784-230124

Freeman, C., Dickinson, K. J. M., Porter, S., and van Heezik, Y. (2012). "My garden is an expression of me": Exploring householders' relationships with their gardens. J. Environ. Psychol. 32, 135-143. doi: 10.1016/j.jenvp.2012.01.005

Glaser, B. G., and Strauss, A. L. (1967). The Discovery Of Grounded Theory: Strategies For Qualitative Research. New York: Aldine. doi: 10.1097/00006199-196807000-00014

Gonzalez, Y., Potteiger, M., Bellows, A., Weissman, E., and Mees, C. (2016). A case study: advancing public health through Gardens for Healthy Communities (GHC) in New York City: The role of anti-obesity objectives in urban agriculture policy. In: Hodges Snyder, E., McIvor, K., and Brown, S. (Eds.), Sowing seeds in the city: Human dimensions (pp. 107-118). Dordrecht, Netherlands: Springer. doi: 10.1007/978-94-017-7456-7_9

Haraway, D. (2008). The Companion Species Manifesto: Dogs, People, and Significant Otherness. Chicago: Prickly Paradigm Press.

Jehlička, P., Daněk, P., and Vávra, J. (2018). Rethinking resilience: home gardening, food sharing and everyday resistance. Canad. J. Develop. Stud. 40, 511-527. doi: 10.1080/02255189.2018.1498325

Jenkinson, C., Layte, R., Jenkinson, D., Lawrence, K., Petersen, S., Paice, C., et al. (1997). A shorter form health survey: can the SF-12 replicate results from the SF-36 in longitudinal studies? J. Public Health. 19, 179-186. doi: 10.1093/oxfordjournals.pubmed.a024606

King, C. A. (2008). Community resilience and contemporary agri-ecological systems: Reconnecting reople and food, and people with people. Syst. Res. Behav. Sci. 25, 111-124. doi: 10.1002/sres.854

Levy, R. I., and Hollan, D. W. (2015). Person-centered interviewing and observation. In Bernard, H. R., and Gravlee, C. C. (Eds.), Handbook of 
methods in cultural anthropology (2 ${ }^{\text {nd }}$ ed., pp. 313-342). London: Rowman and Lifflefield.

Litt, J. S., Schmiege, S. J., Hale, J. W., Buchenau, M., and Sancar, F. (2015). Exploring ecological, emotional and social levers of self-rated health for urban gardeners and non-gardeners: A path analysis. Soc. Sci. Med. 144, 1-8. doi: $10.1016 /$ j.socscimed.2015.09.004

Long, N. J., and Moore, H. L. (2012). Sociality revisted: setting a new agenda. Cambridge Anthropol. 30, 40-47. doi: 10.3167/ca.2012.300105

Longhurst, R. (2006). Plots, plants and paradoxes: Contemporary domestic gardens in Aotearoa/New Zealand. Soc. Cult. Geograp. 7, 581-593. doi: $10.1080 / 14649360600825729$

Magis, K. (2010). Community resilience: an indicator of social sustainability. Soc. Nat. Resour. (2010) 23, 401-416. doi: 10.1080/08941920903305674

Matarrita-Cascante, D., Brennan, M. A., and Luloff, A. E. (2010). Community agency and sustainable tourism development: the case of La Fortuna, Costa Rica. J. Sustain. Tour. 18, 735-756. doi: 10.1080/096695810036 53526

Matarrita-Cascante, D., Trejos, B., Qin, H., Joo, D., and Debner, S. (2017). Conceptualizing community resilience: Revisiting conceptual distinctions. Commun. Develop. 48, 105-123. doi: 10.1080/15575330.2016.12 48458

McDaniel, T., Soto Mas, F., and Sussman, A. L. (2021). Growing connections: local food systems and community resilience. Soc. Nat. Resour. 34, 1375-1393. doi: 10.1080/08941920.2021.1958965

Meinen, A., Friese, B., Wright, W., and Carrel, A. (2012). Youth gardens increase healthy behaviors in young children. J. Hunger Environ. Nutr. 7, 192-204. doi: $10.1080 / 19320248.2012 .704662$

Miles, M. B., and Huberman, A. M. (1994). Qualitative Data Analysis (2nd ed.). Thousand Oaks, California: Sage Publications.

Ochs, E., and Solomon, O. (2010). Autistic sociality. ETHOS. 38, 69-92. doi: $10.1111 / j .1548-1352.2009 .01082 . x$

Okvat, H. A., and Zautra, J. A. (2011). Community gardening: A parsimonious path to individual, community, and environmental resilience. Am. J. Commun. Psychol. 47, 374-387. doi: 10.1007/s10464-010-9404-z

Otsuki, K., Jasaw, G., and Lolig, V. (2018). Linking individual and collective agency for enhancing community resilience in Northern Ghana. Soc. Nat. Resour. 31, 151-165. doi: 10.1080/08941920.2017.1347971

Park, S. A., Shoemaker, C. A., and Haub, M. D. (2009). Physical and psychological health conditions of older adults classified as gardeners or nongardeners. HortSci. 44, 206-210. doi: 10.21273/HORTSCI.44.1.206

Parker, S. L., Godil, S. S., Shau, D. N., Mendenhall, S. K., and McGirt, M. J. (2013). Assessment of the minimum clinically important difference in pain, disability, and quality of life after anterior cervical discectomy and fusion. J. Neurosurg. Spine SPI. 18, 154-160. doi: 10.3171/2012.10.SPINE12312

Pink, S. (2008). Re-thinking contemporary activism: From community to emplaced sociality. Ethnos. 73, 163-188. doi: 10.1080/00141840802180355

Porter, C. M. (2018). What gardens grow: Outcomes from home and community gardens supported by community-based food justice organizations. J. Agric. Food Syst. Commun. Develop. 8, 187-205. doi: 10.5304/jafscd.2018.08A.002

Power, E. R. (2005). Human-nature relations in suburban gardens. Austral. Geograp. 36, 39-53. doi: 10.1080/00049180500050847

Prosperi, P., Allen, T., Cogill, B., Padilla, M., and Peri, I. (2016). Towards metrics of sustainable food systems: A review of the resilience and vulnerability literature. Environ. Syst. Decis. 36, 3-19. doi: 10.1007/s10669-016-9584-7

Pudup, M. B. (2008). It takes a garden: Cultivating citizensubjects in organized garden projects. Geoforum. 39, 1228-1240. doi: 10.1016/j.geoforum.2007.06.012

Ross, H., and Berkes, F. (2014). Research approaches for understanding, enhancing, and monitoring community resilience. Soc. Nat. Resour. 27, 787-804. doi: 10.1080/08941920.2014.905668

Sanjek, R. (1990). Fieldnotes: The Makings of Anthropology. Ithaca, New York: Cornell University Press. doi: 10.7591/9781501711954

Sia, A., Ng, K. S. T., Ng, M. K. W., Chan, H. Y., Tan, C. H., Rawtaer, I., et al. (2018). The effect of therapeutic horticulture on the psychological wellbeing of elderly in Singapore: A randomised controlled trial. J. Therapeut. Hortic. 28, 1-10. Available online at: https://www.jstor.org/stable/10.2307/26598039 (accessed December 6, 2021).
Skog, K., Eriksen, S., Brekken, C., and Francis, C. (2018). Building Resilience in Social-Ecological Food Systems in Vermont. Sustainability. 10, 4813. doi: 10.3390/su10124813

Soga, M., Gaston, K. J., and Yamaura, Y. (2017). Gardening is beneficial for health: a meta-analysis. Prevent. Med. Rep. 5, 92-99. doi: 10.1016/j.pmedr.2016.11.007

Solomon, O. (2012). Doing, being and becoming: The sociality of children with autism in activities with therapy dogs and other people. Cambridge J. Anthropol. 30, 109-126. doi: 10.3167/ca.2012.300110

Strathern, M., Peel, J., Toren, C., and Spencer, J. (1990). The Concept of Society is Theoretically Obsolete. Group for Debates in Anthropological Theory.

Strauss, A., and Corbin, J. (1990). Basics of Qualitative Research: Grounded Theory Procedures and Techniques. Thousand Oaks, California: Sage Publications.

Stroink, M. L., and Nelson, C. H. (2009). Aboriginal health learning in the forest and cultivated gardens: building a nutritious and sustainable food system. J. Agromed. 14, 263-269. doi: 10.1080/105992409027 39737

Tendall, D. M., Joerin, J., Kopainsky, B., Edwards, P., Shreck, A., Le, Q. B., et al. (2015). Food system resilience: defining the concept. Global Food Secur. 6, 17-23. doi: 10.1016/j.gfs.2015.08.001

Twiss, J., Dickinson, J., Duma, S., Kleinman, T., Paulsen, H., and Rilveria, L. (2003). Community gardens: lessons learned from California healthy cities and communities. Am. J. Public Health. 93, 1435-1438. doi: 10.2105/AJPH.93.9.1435

van den Berg, A. E., van Winsum-Westra, M., de Vries, S., and van Dillen, S. M. (2010). Allotment gardening and health: a comparative survey among allotment gardeners and their neighbors without an allotment. Environ. Health. 9, 74. doi: 10.1186/1476-069X-9-74

Vaneeckhaute, L. E., Vanwing, T., Jacquet, W., Abelshausen, B., and Meurs, P. (2017). Community resilience 2.0: Toward a comprehensive conception of community-level resilience. Commun. Develop. 48, 735-751. doi: 10.1080/15575330.2017.1369443

Wakefield, S., Yeudall, F., Taron, C., Reynolds, J., and Skinner, A. (2007). Growing urban health: community gardening in South-East Toronto. Health Promot. Int. 22, 92-101. doi: 10.1093/heapro/dam001

Walsh-Dilley, M., Wolford, W., and McCarthy, J. (2016). Rights for resilience: Food sovereignty, power, and resilience in development practice. Ecol. Soc. 21, 11. doi: 10.5751/ES-07981-210111

White, M. M. (2018). Introduction: Black Farmers, Agriculture, and Resilience. In White, M. Freedom farmers: Agricultural resistance and the Black freedom movement (pp. 3-27). Chapel Hill: The University of North Carolina Press. doi: 10.5149/northcarolina/9781469643694.0 03.0013

Worstell, J., and Green, J. (2017). Eight qualities of resilient food systems: Toward a sustainability/resilience index. J. Agric. Food Syst. Commun Develop. 7, 23-41. doi: 10.5304/jafscd.2017.073.001

Yee Tse, M. M. (2010). Therapeutic effects of an indoor gardening programme for older people living in nursing homes. J. Clin. Nurs. 19, 949-958. doi: 10.1111/j.1365-2702.2009.02803.x

Conflict of Interest: The authors declare that the research was conducted in the absence of any commercial or financial relationships that could be construed as a potential conflict of interest.

Publisher's Note: All claims expressed in this article are solely those of the authors and do not necessarily represent those of their affiliated organizations, or those of the publisher, the editors and the reviewers. Any product that may be evaluated in this article, or claim that may be made by its manufacturer, is not guaranteed or endorsed by the publisher.

Copyright $\odot 2022$ Budowle and Porter. This is an open-access article distributed under the terms of the Creative Commons Attribution License (CC BY). The use, distribution or reproduction in other forums is permitted, provided the original author(s) and the copyright owner(s) are credited and that the original publication in this journal is cited, in accordance with accepted academic practice. No use, distribution or reproduction is permitted which does not comply with these terms. 